\title{
Academic Libraries and the Future: A President's View
}

\section{Robert M. O'Neil}

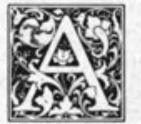

nyone who is not a professional librarian should, I think, come to this occasion with respectable alternative credentials. I am happy to submit mine for your review and appraisal. Being an administrator in a large state university surely gives one a varied perspective on the university library-its problems, its needs, and its hopes. At another level, I have served for several years on the Committee on Research Libraries of the Association of American Universities. Before that time I was a member of the board of the Center for Research Libraries, and since leaving the board I have continued to work with the center as chairman of a small Committee on Financial Resources Development. (The role of that committee, as its title will readily suggest, is to seek additional resources for the work of the center. This prospect is now greatly enhanced, I might say, by the recent appointment of a fulltime development officer.) In several capacities I have been privileged to work with Jim Haas and the Council on Library Resources; two years ago, for example, I was involved in a small group advising on a future course for the council as it faced its second quarter-century. While I suspect Jim and his board could have designed the future without any guidance from our group, we were grateful for the chance to review and assess prospects for this remarkable organization.

What may be the most significant role, however, is one I have left until last in this enumeration. Any university professor with a legitimate claim to scholarship is, of course, a user of the research library. While the pressures of university administration leave regrettably little time for research, an occasional foray to the collections in one's own discipline is a vital source of sanity. Moreover, anyone who uses a specialized or branch library, as I do in my role as law professor, quickly realizes the interdependence of collections across a complex campus. A law library by itself meets only a fraction of the research needs of an active scholar. Increasingly, in fact, my younger law faculty colleagues have interests, and therefore research needs, which transcend the traditional law library collections. They are not only historians and economists with extensive needs in the social sciences; they are also biologists, philosophers, linguists, and anthropologists for whom the core collection of legal materials within the law school building offers but the starting point for their research. So it is as library patron and user that I would offer the most cogent credential of all, and urge that my comments today be taken as much in that perspective as from the administrative vantage point, which presumably occasioned Carla Stoffle's gracious invitation.

Let us suppose we might redesign-or design from scratch-the standards, and the process, by which libraries are judged. Surely if we could do so, we would frame a set of criteria that might differ rather substantially from the often implicit desiderata we now apply. Let me suggest in

Robert M. O'Neil is president, the University of Wisconsin System, Madison. This speech was given at the Association of College and Research Libraries meeting, Los Angeles, California, June 27, 1983. 
somewhat random order several criteria I would propose if we were offered such a tabula rasa.

First, I would seek to appraise interinstitutional cooperation. It would be important to know what priority was given to complementary collection developmentnot only by each college or university as a whole but also by each branch library within a campus community. One might, for example, ask the kind of question that has now been twice asked in our surveys of the libraries of the University of Wisconsin System: How extensive is the duplication among collections, and what steps have been taken to reduce or avoid such duplication? (To my amazement, the initial report of our systemwide library survey several years ago revealed that there was no single edition of a particular work which could be found in every one of the libraries of the University of Wisconsin System. Moreover, the survey discovered a remarkably low ratio of duplication or overlap among the various university collections. A recently updated survey shows within the past three years a very slight increase in that index. The annual report which our Council of University of Wisconsin Libraries is about to present to the Board of Regents will summarize the current conditions in substantially greater detail.)

If interinstitutional cooperation is a valid desideratum, it should be measurable in positive as well as negative terms. Avoidance of duplication or redundancy is the least we should expect; we should also seek positive evidence of complementary collection development in regional and national terms. (During the work of the joint AAU/CLR Task Force on Resource Sharing two years ago we gave considerable attention to this issue. We found particularly useful the national indexes of relative bibliographic strengths developed by the Society of Latin American Librarians and wished that similar lists existed for other disciplines and specialties-as indeed they now may to a greater extent than was true two years ago.) Surely one would expect that major interinstitutional consortia-the Ivy League; the CIC in the Midwest; and the major.
California universities-would have been more aggressive in fostering interinstitutional cooperation in library and collection development than seems to have been the case. If one seeks an explanation for the relative lack of emphasis, perhaps it is that we have simply continued to assume each major research library can be essentially all things to all scholars. Clearly that is not the case, as librarians best understand. Yet the majority of university administrators have not yet accepted the urgency of the need, and thus have not mandated a degree of interinstitutional collaboration which any logical assessment of current conditions would warrant. Suffice it to say that this measure would surely rank high on our list of desiderata-if not in fact (as I would incline to place it) at the very top.

My second goal would be acceptance of new technologies. It would be presumptuous for me as one who yearns nostalgically for the wooden drawer and the familiar card catalog to criticize others for their rates of progress toward the inescapable era of online bibliographic catalogs and other research systems. Yet I have the uneasy feeling that many of us in university administration-sometimes reinforced by the misgivings of conservative faculty colleagues-put library automation low on our lists of equipment and capital priorities. We tend to assume that someone else will meet this need-through special state appropriations, foundation grants, or gifts from a yet unidentified private donor. What we should be doing is to give top priority to such needs both in our requests and in our allocations. If, therefore, we were to judge libraries alone on the rate of technological advance, we would do great injustice to those who administer them and have for years been urging higher support for modernization. Where that change has come too slowly and too late, the onus almost always falls upon administrators outside the library who have simply failed to heed the pleas of their librarian colleagues.

Let me mention a related concern under the heading of technology. Institutions must increasingly be judged by their total adaptation to new methods of scholarly production and information storage. New 
technologies may, for example, profoundly affect the processes of faculty tenure, promotion, and other judgments. Here I might quote a pertinent paragraph from the recent report of the Rockefeller Commission on the Humanities: "The academic system of rewards will have to recognize the new kinds of scholarly achievement made possible by informational technologies. What impact technology will have on the quality of scholarship is under debate; by allowing speedier publication of large quantities of scholarly work, new technologies may also eliminate the process by which additions to humanistic knowledge have always been screened. Assuming adequate processes of review for scholarship published in new modes, committees of appointment and promotion must be willing to consider, say, an electronic printout as part of a scholar's dossier. They should also view essays (published separately from their supporting data) as legitimate and sometimes preferable alternatives to monographs." Any such change in our evaluation of scholarly and creative activity will require significant adjustments within the academic community. And universities ought to be judged by their willingness to make that type of adaptation.

Next on my list of priorities would be preservation. Here again, librarians can hardly be faulted for having muted the alarm. It is those of us in general university administration who have not heeded the alarm, and probably will not do so until each of us finds a treasured volume literally crumbling in our hands as we remove it from the shelves. This challenge was well stated in Patricia Battin's essay in the recent New Directions volume; she observed in her concluding paragraph that "our national heritage is at stake." There has been substantial awareness of the coming crisis within the library community. The Council on Library Resources has for some years given major attention to preservation. Yet it would be difficult to identify within college and university budgets nearly the degree of support for preservation that any rational assessment of the need would suggest-or in many cases any identifiable preservation funding at all. Any catalog of goals or objec- tives would thus surely give heightened attention to this issue.

Fourth, I would ask a clearer appraisal of the role of the library in the total educational process. I would include not simply the obvious correlation between the library collections and the curriculum, especially at the graduate level. We should also appraise the effectiveness of the bibliographic instruction program-chiefly for undergraduate students who have not had prior exposure to a research library, but also for graduate students and even faculty whose limited orientation may inhibit their full enjoyment of the intellectual resources potentially available to them. On this point I would simply note the timely observations which Carla Stoffle, Alan Guskin, and Joseph Boisse have advanced in their fine essay on the educational mission of the university library soon to appear in another New Directions volume. They have stressed the central importance of a bibliographic instruction program requiring as it does the active involvement of several sectors of the academic community. I will say no more, since one of the coauthors is a member of the panel and may well wish in his comments to elaborate.

Before leaving this theme of educational mission, some comment might be made about the contribution of libraries to nontraditional learning. Clearly the eighties will be a time of expanded emphasis for learning opportunities beyond the formal college classroom. Not only through new technologies, but also through greater willingness to take instruction to less mobile students, we are seeking ways to diversify the learning experience. What has not been fully addressed is the potential role of libraries in nontraditional learning situations. Those technologies, for example, which transmit the professor to the student's home should also make library resources available to the immobile or physically remote learner. Indeed, if higher education is to meet the challenge of nontraditional learning in the eighties and beyond, the question of bibliographic access simply must be considered along with more obvious and more familiar challenges of extended learning.

Let me turn from education to gover- 
nance. Clearly participation in decision making is a two-way process. On my list of goals, therefore, I would place both aspects-the role of the library in the governance of the university, and the role of faculty users in the governance of the library. The first dimension is relatively familiar and comfortable; the second is more sensitive. We might spend a few moments on each.

Much more could be done to enhance the involvement of librarians in general university governance. Faculty senates and councils should routinely include professional librarians either as a separate constituency or through established representative channels. The dean or director of libraries should, of course, participate in the central academic body of the campus. Librarians should have meaningful access to the university's governing board-for example, in forums such as the annual report to our regents from the Council of University of Wisconsin Libraries. Committees which advise on fiscal and budget decisions should routinely have library membership, or at least provide ample chance for presentation of library perspectives. The review of both present and proposed degree programs must include an assessment of library resources and implications. In these and perhaps other ways, meaningful participation of the library in university governance can be enhanced. All this is relatively familiar and has been addressed more fully elsewhere.

The other side of the equation may cause greater concern. Librarians may be understandably uncomfortable about faculty library committees and their potential for interference in library policy matters. As one who has written extensively about the need to maintain maximum intellectual freedom in the selection and dissemination of library materials, I would be the first to resist improper intrusion-as much by user committees as by meddling administrators. Yet the full potential of teaching faculty committees may not be fully appreciated within the library community. Such groups are, for example, buffers between less sensitive colleagues across campus and the professional librarians who can never honor all requests for new monographs or journals. These groups can help to explain and justify library policies on faculty borrowing, access to studies and carrels, library hours, and many other sensitive issues on which the library administration should not alone be expected to bear the burden. In short, a reasonable criterion would be the receptiveness of librarians to the benign involvement of such groups-while insisting upon keeping such committees at arm's length during decisions of only internal import.

Governance is, as I suggested earlier, a two-way process. Librarians legitimately seek-and should have-more extensive involvement in university decisionmaking processes. In return, however, they should be willing to accept a greater measure of faculty involvement in library decision making-including some of the most difficult decisions: to reduce serial subscriptions, to relocate certain collections in remote storage facilities, to change staffing patterns, and, of course, to automate both circulation and bibliographic systems. Only reciprocity in the matter of governance will ensure its effectiveness.

Finally, I would borrow from my own professional interests a goal which to librarians may seem so obvious as hardly to need separate mention: commitment to the protection and preservation of intellectual freedom. If the university as a whole should be a bastion of academic freedom and free inquiry, then the university library should be at the core of that commitment. Seldom, of course, are college and university libraries faced with crude censorship threats of the kind that increasingly these days beset school and public libraries. Censorship as such is seldom the issue for the university research librarian. Yet I wonder if those who enjoy the far greater measure of freedom in higher education might not take a more active role in protecting the acquisition and dissemination of controversial materials in other sectors. The American Library Association has within the past decade made a major commitment-through its Office of Intellectual Freedom, the Freedom to Read Foundation, and a major program of litigation on behalf of libraries and librarians. Some university librarians 
have played a major part in these initiatives. But it seems to me the whole university library community might well make the cause of intellectual freedom at the elementary and secondary level, and in public library systems, a topic of greater concern and active support. Perhaps we do not always appreciate that censorship in the schools could in time jeopardize academic freedom in higher education as well. Recall, for example, the original Arkansas creationism law struck down by the United States Supreme Court in 1968. While originally aimed at the teaching of evolution only in the elementary and secondary schools, it eventually reached also the classrooms, laboratories, and libraries of the University of Arkansas and other publicly supported institutions of higher learning in the state. Loyalty oaths were not aimed only at elementary and secondary teachers, but came in time to include state college and university faculty-and in Massachusetts even purported to bind Harvard, MIT, and other private university professors as well. Some recent initiatives of the moral majority have looked initially at problems in the public school classroom but have not been wholly unmindful of possibly fertile ground in higher education as well. Thus, it seems to me, the university librarian disassociates himself or herself at some peril from the more vulnerable school or public librarian. It is for this reason that I would add the protection of academic and intellectual freedom at all levels to my list of criteria for the college and university library.

If these are the goals, how might a new system of evaluation better reflect them? Obviously I have no simple solutions. Per- haps, however, a few thoughts on our current judgment process might be helpful.

For one, I would deemphasize currently quantitative measures of library status such as the annual ARL statistical rankings. Such measures-useful though they are for some purposes-may not only fail to serve these goals; they may actually, if subtly, disserve our broader objectives. To judge the quality of libraries, for example, only by the number of volumes currently held or the number added each year may encourage the very competitive behavior which a commitment to interinstitutional cooperation and complementary collection development would deter. Moreover, to exalt the number of new acquisitions or the number of separate journal titles does little to encourage active preservation of current materials. Might there be some way in which the ARL surveys would include-even in their quantitative datasome measures of success in reducing duplication within and between institutions or improving preservation of existing materials? And beyond these obvious quantitative dimensions, could we not-perhaps through the regional and specialized accreditation process-give greater attention to intangible factors like governance, bibliographic instruction, professional service, and protection of intellectual freedom-all of which are as vital to the role of the university library as they are elusive of measurement?

This is clearly the place to post questions and challenges, rather than to provide answers. Moreover, those who may have the answers are those far more expert in library matters than I. 